\title{
e-Interview
}

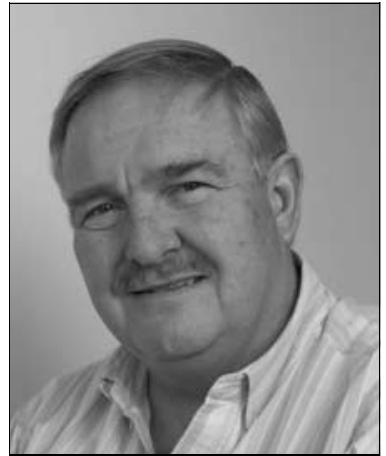

\section{David Nutt}

David Nutt is Professor of Neuropsychopharmacology at Imperial College London. He trained at Guy's Hospital and Oxford. His special interests include neuropsychopharmacology, addiction, anxiety and sleep.

\section{If you were not a psychiatrist, what would you do? \\ Probably neurology or clinical pharmacology.}

What has been the greatest impact of your profession on you personally? It has made me think more broadly about issues of health, liberty and justice. It has challenged my preconceptions and prejudices about myself, my profession and the doctor-patient relationship, while seeing how some colleagues shy away from the challenging issues.

\section{Do you feel stigmatised by you} profession?

Not at all - with a name like mine it might have been pre-destined!

What are your interests outside of work? Since autoimmune arthritis destroyed my sporting ability (I used to be quite good at golf, badminton, squash and cricket), I am heavily into my gardens and orchards.

Who was your most influential trainer, and why?

As a lecturer in Oxford I came under the supervision of Michael Gelder - a master of critical evaluation and a source of vast knowledge.

What job gave you the most useful training experience?

Child neuropsychiatry at the Park Hospital in Oxford: this taught me a lot of knowns that were unknown to me as well as how to work with children and families.

\section{Which publication has influenced you} most?

Virkkunen M, De Jong J, Bartko J, Goodwin FK, Linnoila M. Relationship of psychobiological variables to recidivism in violent offenders and impulsive fire setters. A follow-up study. Arch Gen Psychiatry 1989; 46: 600-3. Biological determinism at its best - it shows the challenge psychiatry faces in helping people whose brain and brain chemistry collude against them to produce extreme vulnerability to actions they would rather resist.

How has the political environment influenced your work?

It sure has had a huge impact. Being sacked as Chair of the Advisory Committee on the Misuse of Drugs for political reasons had a major impact: lots of extra work but a great deal more people understanding my approach and reasons (and largely agreeing with me).

\section{What part of your work gives you} the most satisfaction?

Teaching trainees about how research explains clinical practice.

\section{What do you least enjoy?}

Form filling.

What is the most promising opportunity facing the profession?

Regaining control of the psychiatry treatment agenda; as science helps us explain treatment, we can justify better what we do and hopefully develop ways to do it better.

What is the greatest threat?

National Health Service reforms that will further marginalise funding for psychiatry treatments.
What single change would substantially improve quality of care?

Budgets for psychiatry commensurate with the costs of the illnesses.

What conflict of interest do you encounter most often?

Patients not getting referred for second opinions and specialist treatment because general practitioners won't pay.

What is the role of the psychiatrist in countries emerging from conflict? Support the traumatised and provide a balanced view for healthcare providers.

What is the most important advice you could offer to a new trainee?

Question - question - question.

What are the main ethical problems that psychiatrists will face in the future?

Electronic tagging of patients on involuntary detention orders.

What is the role of the psychiatrist in rebuilding healthcare systems? Provision of vision and balance, maturity and wisdom.

What single change to mental health legislation would you like to see? No opinion.

What single area of psychiatric practice is most in need of development? Adolescent psychiatry.

What single area of psychiatric research should be given priority? Addiction.

How would you like to be remembered?

As the man who helped make sense of the $p$ (harmacology) in psychiatry.

Dominic Fannon

doi: $10.1192 / p b . b p .111 .034595$ 